\title{
Remembranzas de una generación
}

\section{A generation remembrance}

Lic. Gloria Hernández Orozco

\section{¿Recuerdas colega, aquel marzo del 52? \\ Cuando ingresaron a la ENEO - UNAM \\ Un grupo de adolescentes \\ acabadas de llegar \\ De Guerrero, Tampico, Oaxaca, Veracruz y Minatitlán \\ Entre algunas entidades y rumbos de esta Ciudad. \\ Deseaban ser Enfermeras ¿sabrían su significado? \\ Ahora podemos saberlo \\ Pues de éste hecho colega \\ Cinco décadas, más ocho han \\ pasado.}

Comparte conmigo como nace

esta historia...

En la calle de Donceles, "Pasaje

Catedral"

Fue a las doce la cita... cuando

tuvimos que presentar:

Dos batas mil rayas, medias

blancas, capa oro y negro,

Maletín e instrumental y zapatos

de enfermera que tuvimos que

comprar.

La primera etapa no la olvido

¡Unifórmate bien y aprende niña!
Nos repetían sin descansar

Porque tendrás como premio el

"peto" y la "toca"

Que en significativa ceremonia, te impondrán.

Pero antes quiero decirte y no con poca tristeza

Que aquel grupo numeroso dividió su destino

$\mathrm{Al} \mathrm{H}$. Juárez se fue un grupo y otro hacía el H. General

Tomo su nuevo camino.

Abordamos todas con interés

los nuevos saberes en

Propedéutica, Anatomía, Higiene

y Medicina Preventiva,

Pediatría, Farma, Patología,

Trabajo Social y Terminología

Médica

Con raíz griega que tuvimos que

estudiar.

También Gineco, Patología, Medico Quirúrgica y Psicología

Poco a poco cambiaron nuestra estructura mental...

Bajo los grandes arcos del $\mathrm{H}$.

Juárez,

Y frente a la fuente del pabellón 25

del H. General
Cuando en grupo nos

reuníamos a estudiar.

Una mención especial para algunas merece, La práctica de disección

en el anfiteatro,

Pues nunca pensamos

Anatomía aprender,

Temblando o sudando a ratos

y aguantando

El hedor que despide morir

todo ser humano.

Recuerdas a los Profres. Leyja, Canales, Kawe, Peón del Valle,

Pavía, Fernández de Castro, Pliego, Blanco y Leal, Perea,

Sola, Amor, Alvirez y Jiménez, que entre nosotras no están

Todos empeñaron en transformar ese grupo de estudiantes,

En un semillero excepcional

Compartieron el mismo propósito los profres. Buentello, Mejía,

Corona,

Segura Albiter, Guevara Rojas, Contreras y Tovar.,

Todos ellos insignes académicos de nuestra Universidad.

कै\%?

Licenciada en Enfermería y Obstetricia ENEO-UNAM

Correspondencia: gloho36@hotmail.com 
La práctica hospitalaria no la debemos olvidar,

Que bien por las profras.

Enfermeras de calidad,

A la cabecera del paciente, anciano, adulto,

Madre o infante, sin importar sexo

o edad

Nos enseñaron que plan de

cuidados debíamos aplicar.

¿Están en tu mente colega, aquel

grupo de profras.

Que la UNAM decidió formar

coordinadas por la chilena

Lozzier, antes brillantes damas,

Estela Corona, Sor Cerisola, Maza

Brito,

Otero, Islas y otras enfermeras

más.

También las que estuvieron día a

día guiando nuestro camino

Juventina, Sara Alicia, Irma

González, Carmelita, Esperanza,

Conchita,

Pineda, Herlinda y Cholita las

recordamos con especial cariño.

Que imponentes los pabellones y

las salas del hospital, la 15, 17 y 20,

...el 13, 24 y 30 de maternidad,

nunca tan grandes fueron colega,

Como nuestras dudas y nuestra

ingenuidad,

Las "Primeras", las "Mayores"...

que solemnes... los pacientes,

Que tristeza... que gran

responsabilidad.

Aquel "Concurso de Vendajes",

contienda sin igual,

Entre charpas, capelinas, espigas

y circulares

El cronometro fue un juez

imparcial,

Al cubrir "de ipsofacto" a nuestra

victima ¡claro!
Con beneplácito del autor del libro

Vendajes, el Dr. Sandoval.

Cuantas metas cumplimos para

cubrir nuestro plan...

Del panteón se facilitó traer

huesos, para comprender

Anatomía,

Fue necesario investigar como

tratan las "aguas negras"

Observando siempre y aclarando

dudas, que surgían día con día.

El Hospital de la Mujer

nos mostró esos años,

Y no con poca crueldad,

que una sexoservidora

Adquiere y transmite

enfermedades venéreas

$\mathrm{Y}$ vive al margen de la sociedad.

Además si estoy en lo cierto

durante la práctica de Trabajo

Social,

La Casa Cuna dejó nuestro

corazón en un puño, y en la

Cara humedad, al valorar la

soledad de los pequeñitos

Afectados por la orfandad.

El BVA ¿lo recuerdas?...

Centro de Salud ejemplar,

Facilitó nuestra experiencia,

realizando en los hogares,

Acciones preventivas concretas,

con una visión futurista

De los programas llamados

"Proyección a la Comunidad".

Con cierto temor acudimos

a la "Peni" y a la Castañeda

Escenarios que aportaron

experiencia y momentos

para reflexionar

Sobre el amplio significado

de la salud biopsicosocial
El H. Gastón Melo y Salas 10 y 14

¡que experiencia!

Nos mandaron a velar, dando

cuidado al paciente,

En la noche colega, no solo a ser

Enfermera se aprende

Sino el sueño a aquilatar.

Ahora quiero recordarte un

momento particular,

"la petición al árbol",

que en forma fraternal nos

Reunió en los jardines del $\mathrm{H}$.

Juárez, un deseo en grupo evocar.

Cuantos años han pasado, Colega

y aún recuerdo con claridad

Los cuidados al nacimiento de un

niño y la atención de un paciente

En su momento final... emociones que estremecen, pero que a la vez nos reportaron tanta

responsabilidad.

Rápido paso el tiempo

preparándonos cada vez más,

Cuantas alegrías y tristezas nos

hicieron madurar,

Estarás de acuerdo conmigo

Colega que nos formaron como

Enfermeras,

Para servir a la humanidad.

Y por fin llego el día, Colega

culminamos la carrera con

felicidad,

La luz simbólica de Florence

Nightingale prendimos, más no en

Crimea, sino en el Anfiteatro

Bolívar de nuestra Universidad,

A los acordes de "Pompa y

Circunstancia”, la ceremonia

concluyó con

Sobriedad y hacía la Basilica

nos fuimos a postrar. 


\section{Enfermería Universitaria}

Fue el invierno del " 54 ",... cuando aquel grupo transformado, Se incorporó a las instituciones que tanto había anhelado Otras tantas nos quedamos un poco más en la aulas, Estudiando Gineco - Obstetricia, para asistir a las madres Que un nuevo ser estaban esperando.

El mercado de trabajo con paciencia al grupo aguardó Que acumulara experiencia y mayor preparación,

Algunas ejercieron su sapiencia en áreas de atención directa, Otras más en centros formadores de nuevas colegas y

También aportamos saberes en los niveles de decisión.

Entre las instituciones que han sido Colega, nuestro campo profesional Mencionaremos a la UNAM, Inst. Nal de Cardiología, Secretaría de Salud, Servicios Médicos del ISSSTE, IMSS, PEMEX, DDF, el Inst. Nal. de laNutrición, Inst. Nal. de Pediatría, siempre abrieron Sus puertas en diferentes niveles de participación, contribuyendo A cumplir sus metas de salud a la población.
Mencionar debemos, que algunas Colegas

Detuvieron sus pasos a mitad del camino...

Pero siempre las recordamos con especial cariño.

Si a la fecha el grupo permanece unido,

Nos debemos felicitar

a la convicción de cada una,

Sin duda se ha debido,...

pero sin temor a exagerar,

Sabemos que MIGUE

lo ha promovido...

Pues días antes de su cita

tu teléfono hizo sonar.

MIGUELINA MORALES

ECHAZARRETA DE GARCÍA -

"La AbUelA" le decíamos Colega, con un profundo cariño

Pues siempre se preocupo por brindarnos su ayuda, interés y alivio.

¡Hoy podemos evaluar Colega, al grupo muy satisfechas

Hay logros, buenos frutos de cosecha

Después de una larga vida profesional.

En resumen pasaremos lista a la generación Presente el grupo de jubiladas por los años de profesional labor, Sonrientes y plenas las que desde sus hogares, Como esposas y madres ejemplares ofrecieron su dedicación, Y presentes... quienes con la conciencia de alta responsabilidad Profesionalizaron su formación en ENFERMERÍA y en otras áreas Para ejercer con eficiencia profesional su labor.

Finalmente con gusto te digo Colega...

En ésta etapa de la vida y con tantos años de jubilación, Seguimos acudiendo a la cita mensual que el tiempo ya perpetuó.

Con cariño para uds.

GLORIA HERNÁNDEZ OROZCO

México, Abril 2010.

Para ti Estela Hernández Osorio, mi fraternal gratitud, Por tu asertiva firmeza, que modificó mi actitud Al mostrarme tu habilidad $y$ destreza, Que reorientó mi vocación. 